OPEN ACCESS

Edited by:

Marina Milner-Bolotin, University of British Columbia, Canada

Reviewed by Taro Fujita

University of Exeter, United Kingdom

Kwesi Yaro,

University of Alberta, Canada

*Correspondence:

Jack A. Dieckmann jackd1@stanford.edu

Specialty section: This article was submitted to

STEM Education,

a section of the journal

Frontiers in Education

Received: 27 September 2021 Accepted: 23 November 2021 Published: 10 December 2021

Citation:

Boaler J, Dieckmann JA, LaMar T, Leshin M, Selbach-Allen $M$ and

Pérez-Núñez G (2021) The

Transformative Impact of a Mathematical Mindset Experience

Taught at Scale.

Front. Educ. 6:784393.

doi: 10.3389/feduc.2021.784393

\section{The Transformative Impact of a Mathematical Mindset Experience Taught at Scale}

\author{
Jo Boaler ${ }^{1}$, Jack A. Dieckmann ${ }^{1 *}$, Tanya LaMar ${ }^{1}$, Miriam Leshin ${ }^{1}$, Megan Selbach-Allen ${ }^{1}$ and \\ Graciela Pérez-Núñez ${ }^{2}$
}

${ }^{1}$ Graduate School of Education, Stanford University, Stanford, CA, United States, ${ }^{2}$ Inter-American Development Bank, Washington, DC, United States

A wide range of evidence points to the need for students to have a growth mindset as they approach their learning, but recent critiques of mindset have highlighted the need to change teaching approaches, to transfuse mindset ideas throughout teaching. This shifts the responsibility from students themselves to teachers and schools. This paper shares a mixed methods study conducted across the US, that measured the impact of a "mathematical mindset teaching approach" shown to be effective when taught by the authors, scaled to teachers in 10 US districts. The effectiveness of this novel mathematics approach was measured using pre and post assessments during a summer intervention followed by measures of GPA change when students returned to schools. Both measures showed that a mathematical mindset approach to teaching significantly improves students' mathematical achievement, and changes students' beliefs about themselves and their approach to learning. Accompanying analyses of teaching and of teacher interviews give insights into the ways students change, highlighting the need to bring about shifts in students' mindsets through a changed approach to mathematics teaching and learning.

Keywords: Mindset, Mathematics, teaching, learning, beliefs, student math Learning, student math Achievement

\section{INTRODUCTION AND LITERATURE REVIEW}

In recent years there has been considerable attention paid to the idea of mindset, a construct developed and researched by Carol Dweck and teams of other researchers (Dweck, 2007). Dweck has shown that students with a "growth mindset", who believe that they can learn anything and that their intelligence develops as they learn more, outperform those with a fixed mindset who believe their intelligence is fixed (Aronson et al., 2002; Good et al., 2003; Blackwell et al., 2007). Dweck's book summarizing mindset is an international best seller (Dweck, 2007) and her ideas have been used by tens of thousands of schools worldwide, as well as businesses, sports teams, and parents. Despite the extensive research base showing the impact of mindset changes, critiques of the concept have emerged. Dweck herself has now written about the dangers of "false growth mindset" work in schools, when teachers learn only to praise effort, but do not implement teaching strategies to help develop growth mindsets. Kohn (2015) argues that teachers and administrators who urge students to change their mindset without changing the teaching environment are doing them a great disservice, merely shifting the responsibility and perhaps blame onto students. This paper shares a teaching approach that is particularly important in light of the mindset critiques. The approach that will be examined in this paper differs from many mindset initiatives as it infuses mindset ideas and brain 
science messages throughout mathematics teaching. In doing so, the approach takes account of both Dweck and Kohn's warnings and critiques, shifting the responsibility for mindset awareness from students to teachers and schools. The approach was enacted in ten school districts across the United States resulting in significant mindset and mathematics achievement gains.

Multiple research studies have demonstrated the positive impact of having a 'growth mindset' in mathematics and other subjects. Blackwell et al. (2007), for example, followed students with a growth and fixed mindset during seventh and eighth grade, who were taught by the same teachers, to look for impact on mathematics achievement. They found that those with a growth mindset pulled increasingly ahead and by the end of eighth grade their achievement was at a significantly higher level than those with a fixed mindset, even though they were taught in the same classes and by the same teachers. In an interventional study building upon their prior work, Blackwell et al. (2007) performed a growth mindset intervention with students of color $(97 \%$ African American and Latinx) making the transition to seventh grade, many of whom were already showing declining grades. The control group received eight sessions of training in study skills, while the growth mindset group received eight sessions of study skills plus training in growth mindset. The key growth mindset message was that effortful learning changes the brain by forming new connections, and that students control this process. The growth mindset intervention led to a 0.25 difference (on a 4.0 scale) in mathematics grades between the experimental and control conditions (adjusting for preintervention differences).

Good et al. (2003) also created a growth mindset intervention for seventh grade students (largely Latinx) and compared it to a control group that received an anti-drug workshop. In both groups, mentors met with their students in person for $90 \mathrm{~min}$ at two separate times. The impact of the intervention on statewide end-of-year achievement test scores was assessed. The growth mindset intervention led to significantly higher achievement in mathematics and reading test scores. Moreover, in the control group, the gender difference in mathematics was highly significant, but in the growth mindset group the gender gap was largely eliminated.

Finally, a study with college students looked at the impact of growth mindset on overall grade point average compared to two control groups, a multiple intelligence intervention and a no-treatment control (Aronson et al., 2002). While the control groups showed no change in achievement, the growth mindset intervention led to a clear gain in achievement, particularly for African American students. In the following term, African American students gained one quarter of a grade point, and the grade-point gap between White and African American students was no longer significant. In addition, the African American students in the growth mindset group showed a significant increase in their valuing and enjoyment of academics.

Taking the growth mindset message beyond the traditional boundaries of classrooms and schools, Boaler et al. (2018) developed an online course entitled 'How to Learn Mathematics' that shares information about mindset and productive mathematics learning through a massive, open, online course (MOOC), taken by approximately one half of a million people. In a randomized controlled trial investigating its impact, middle school teachers teaching two classes were recruited to give the online course to one of their classes. The students in both experimental and control groups were then followed over a school year. At the end of the school year the students who took the online course achieved at significantly higher levels than those who did not on standardized, Smarter Balanced state scores. The students were also $68 \%$ more engaged in work, as measured by their teachers in their mathematics classes, and they changed their mindset and ideas about mathematics significantly (Boaler et al., 2018).

These different studies all suggest that when students change their minds about what is possible, and they are released from ideas of fixed intelligence, they achieve at higher levels, whether or not the teaching they receive changes. Despite this, Kohn (2015) has cautioned that it is irresponsible to tell students that they need to change their ideas, without changing the school systems they work within. We support this view and recognize that many parts of the school system communicate messages about mindset to students, such as assessment, grading, other forms of feedback, student grouping, and even the nature of the questions used in classrooms (Kraker-Pauw et al., 2017). This study shares a teaching approach in which mindset ideas are infused throughout the teaching practices used by teachers, as part of a summer intervention.

A key part of a mathematical mindset teaching approach (Boaler, 2016, 2022) is the use of open tasks, that are "low floor and high ceiling"-these are tasks that all students can access but that extend to high levels, and that can be approached in multiple ways. Mathematics classrooms are typically filled with closed, narrow questions-that can contravene growth mindset messages. Students often interpret mathematics as a fixed subject, as questions have one right answer with one valued method. If questions are, by contrast, open, with invitations to students to draw, discuss, and make connections with prior knowledge, then they are more likely to see mathematics as a growth subject that they can learn (Boaler, 2002; Boaler, 2019a). These types of tasks also allow students to engage in authentic mathematical thinking and reasoning in ways that more traditional problem sets do not allow (Schoenfeld, 2016).

While traditional narrow questions communicate to students that mathematics is about recalling and applying a procedure, open tasks provide opportunities for students to engage in what Stein et al. (1996) call "doing mathematics" that is: "framing and solving problems, looking for patterns, making conjectures, examining constraints, making inferences from data, abstracting, inventing, explaining, justifying, challenging, and so on" (p. 456). Rich mathematical tasks also support the development of autonomous learners, as students are not dependent upon reproducing the teacher's example to gain the correct solution, rather they are encouraged to follow their own creative thinking and ideas (Silver and Stein, 1996; Silver, 1997). Several studies have shown the connection between the use of open tasks and the development or strengthening of students' growth mindsets (Boaler, 1998; Stohlmann et al., 2018; Sun, 2018). 


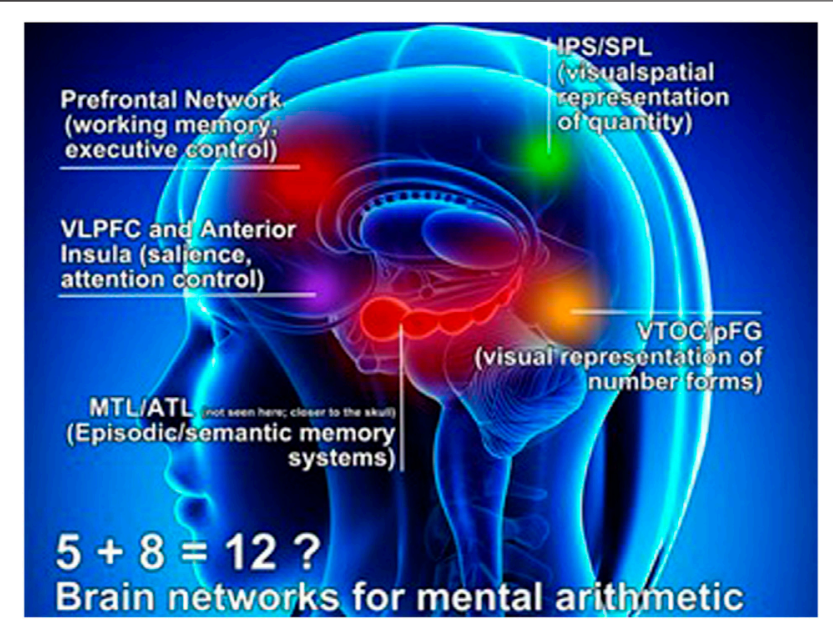

FIGURE 1 | Brain network underpinning mathematics knowledge, lang chen in Boaler (2019a).

Some of the growth mindset information that is most powerful to students draws upon the evidence from neuroscience, showing the potential of the brain to grow and develop connections (Maguire et al., 2006; Iuculano et al., 2015; Boaler, 2019a). Additional neuroscientific evidence that underpinned the teaching intervention was the evidence showing that brains are made up of 'distributed networks', and when people work on mathematics problems, different areas of the brain light up and communicate with each other (Menon, 2015). In particular, brain activity is distributed between different networks, which include two visual pathways: the ventral and dorsal visual pathways (see Figure 1). Neuroimaging has shown that even when people work on a number calculation, such as $12 \times 25$, with symbolic digits (12 and 25), mathematical thinking is grounded in visual processing.

The dorsal visual pathway has reliably been shown to be involved when both children and adults work on mathematics tasks. This area of the brain particularly comes into play when students consider visual or spatial representations of quantity, such as a number line. A number line representation of number quantity has been shown in cognitive studies to be particularly important for the development of numerical knowledge and a precursor of children's academic success (Siegler and Booth, 2004; Hubbard et al., 2005; Schneider et al., 2009; Kucian et al., 2011).

The different studies on mindset and on teaching with a growth mindset suggest that while mindset interventions aimed at changing students' ideas can be powerful, the biggest improvements can be brought about when students' ideas change at the same time as teaching is designed to encourage a growth mindset (Anderson et al., 2018; Boaler, 2019a). The approach of changing students' ideas and changing teaching, with a mathematical mindset intervention, has not, before now, been studied. This paper shares research that investigates the impact of mathematical mindset teaching, implemented by multiple teachers in ten school districts distributed across the United States.
The Mathematical Mindset teaching approach was first developed and studied in a youcubed summer camp implemented in the summer of 2015 and detailed in Boaler (2019a, b). Eighty-one students who had just finished sixth or seventh grade attended a four-week mathematics camp, held on a university campus. The students were recruited from two local school districts, had been identified by administrators as having had negative math experiences, and were from a range of ethnic backgrounds, with the majority of students identifying as mixed race. Mindset was infused in two ways: (1) the teaching of mathematics through a curriculum of open tasks that can be approached in different ways and (2) explicit growth mindset messaging. Students engaged in low-floor, high-ceiling tasks, and the four weeks of teaching were centered around four "big ideas" (California Department of Education (CD), 2021; Cabana et al., 2014; Bransford et al., 2000): number sense, pattern seeking, algebra as a problemsolving tool, and generalizing. Additionally, teachers explicitly communicated messages about growth mindset and brain science, highlighting the importance of mistakes, struggle, and visual thinking, and dispelling myths about the importance of speed and procedural approaches to mathematics. Analyses of students' achievement on a standardized assessment of algebraic thinking that was taken before and after camp revealed that students improved their performance by an average of 50 percent across the students, with an effect size of 0.91 standard deviation, equivalent to 2.8 school years of growth in school (Boaler, 2019b). Additionally, qualitative analyses of student interviews revealed that the majority of students shifted their perspectives over the course of summer camp, changing their minds about their own potential and about the nature of mathematics (Boaler 2019b). In particular, they began to see themselves as capable, they saw mathematics as a creative set of ideas, and they saw their role in mathematics as people who investigated ideas, explored conjectures, and reasoned about them (see also: https://www.youcubed.org/resources/solvingmath-problem/)

While the results of the original youcubed camp were promising, several important questions remained. Could the mathematical mindset approach to teaching only be done by this particular teaching team at this particular university? Could it be specified well enough to scale this approach to other summer programs? If so, would students at other programs experience increased achievement and shifts in mindset as a result? The remainder of this paper will communicate the results of a study monitoring the impact of the youcubed summer camp, taught in ten districts across the United States, considering any potential improvements in mathematics achievement after the camp and when the students returned to their mathematics classes in the following school year.

Over several years, workshops designed by the research team were offered for teachers to learn about the mathematical mindset teaching approach. During the workshop teachers were given the curriculum and trained with mathematical mindset pedagogical practices, and multiple additional resources were shared with them to support their learning on this teaching approach. In 2019 
TABLE 1 | Characteristics of participating school districts.

\begin{tabular}{|c|c|c|c|c|c|c|}
\hline School district & State & $\begin{array}{l}\text { Urban/Rural } \\
\text { classification }\end{array}$ & Total students & $\%$ Black & $\%$ Latino & $\begin{array}{c}\% \text { Free/ } \\
\text { Reduced price } \\
\text { lunch }\end{array}$ \\
\hline District 1 & Michigan & Suburb: Large & 3,258 & 24 & 3 & $48 \%^{a}, b$ \\
\hline District 2 & Alaska & City: Small & 13,780 & 5 & 9 & $31 \%^{\mathrm{b}}$ \\
\hline District 3 & California & Suburb: Mid-size & 9,494 & 3 & 78 & $80 \%$ \\
\hline District 4 & Illinois & Suburb: Large & 20,973 & 5 & 38 & $41 \%^{\mathrm{b}}$ \\
\hline District 5 & New Mexico & Rural: Fringe & 2,026 & 0 & 79 & $62 \%$ \\
\hline District 6 & Illinois & Suburb: Large & 6,827 & 3 & 42 & $58 \%$ \\
\hline District 7 & Illinois & Suburb: Large & 38,934 & 7 & 54 & $59 \%$ \\
\hline District 8 & Illinois & Suburb: Large & 8,580 & 2 & 16 & $15 \%^{\mathrm{b}}$ \\
\hline District 9 & California & Suburb: Large & 1,531 & 1 & 61 & $53 \%$ \\
\hline District 10 & California & City: Small & 4,637 & 1 & 38 & $41 \%^{b}$ \\
\hline
\end{tabular}

Source: NCES Common Core of Data, most recent available school year (2017-18).

${ }^{a}$ Data source for this statistic is Michigan Student Data System (NCES data not available for that year).

${ }^{b}$ Camp attendees differ from overall student population of district, with at least $50 \%$ experiencing poverty.

TABLE 2 | Camp implementation characteristics, by district.

\begin{tabular}{|c|c|c|c|c|}
\hline School district & Days of instruction & $\begin{array}{c}\text { Hours } \\
\text { of math instruction }\end{array}$ & Student enrollment & $\begin{array}{c}\text { Share of students } \\
\text { who attended } 75 \\
\text { (\%)or more days } \\
\text { of camp }\end{array}$ \\
\hline District 2 & 12 & 72 & 47 & 85 \\
\hline District 3 & 10 & 30 & 78 & 86 \\
\hline District 4 & 16 & 80 & 66 & 100 \\
\hline District 7 & 28 & 84 & 107 & 60 \\
\hline District 8 & 23 & 40 & 70 & 66 \\
\hline District 9 & 12 & 36 & 24 & 83 \\
\hline District 10 & 10 & 30 & 45 & 42 \\
\hline
\end{tabular}

a partnership between ten school districts and youcubed enabled a study of the learning of students who participated in the camps in their districts, which is the focus of this paper.

\section{RESEARCH DESIGN}

In the summer of 2019, ten districts in five states implemented the youcubed summer camp, agreeing to provide data on their students' mathematics achievement at the beginning and end of the camp and later when the students returned to school. The districts recruited students to attend the youcubed camps who were diverse in terms of ethnicity, gender, and socioeconomic status. Additionally, district recruitment focused on students who are Black, Latinx, and/or experiencing poverty, to ensure that camp attendees reflected these groups. Overall district data is shown in Table 1. Camps also exhibited variation in enrollment size, attendance rates, and amount of instruction delivered, which is shown in Table 2. The duration of camps analyzed for this study ranged from 10 to 28 days, comprising $30-84 \mathrm{~h}$ of math instruction in the summer of 2019. The wide range in implementation characteristics provides important context for this analysis.
Different forms of support were offered to participating teachers before and during the study summer camps. In the spring of 2019, all participating teachers were required to take part in three 1-h webinars and were offered additional learning opportunities, including a book detailing the approach (Boaler, 2016) and an online class that shared videos and teaching designs from the original camp (https://www.youcubed.org/ mathematical-mindsets/).

Teachers of the multiple camps were all given detailed curriculum that described the objectives and activities for each lesson during the camp. Two sequences of the curriculum were shared with teachers to account for the variation in instructional days across the sites: one for twoweek camps expected to include $30 \mathrm{~h}$ of instruction, and one for four-week camps expected to include $60 \mathrm{~h}$ of instruction. The mathematical topics included in the curriculum were number sense, algebra as a tool for problem solving, generalization and mathematics as pattern seeking. Additionally, specific structures and activities were provided. A typical day included a "number talk" to build number flexibility and a short video with growth mindset messages. The remaining time was dedicated to instruction organized into "big ideas," with students engaging in an 
orientation activity, open-ended mathematics tasks that encouraged then to engage with agency and authority (Gresalfi and Cobb, 2006; Sengupta-Irving, 2016), time to work in groups, and often a whole class discussion.

\section{Research Methods}

Given the goal of understanding the impact of a mathematical mindset approach taught within summer camps, scaled to ten districts, a mixed methods approach was implemented, drawing from both quantitative and qualitative methods. A matched comparison analysis was employed to assess the effect of the approach on students' achievement. School districts provided a variety of achievement measures of both participant and nonparticipant students (GPA and MARS scores, before and after camp participation; and a baseline math standardized test score), and a battery of control variables (race, ethnicity, gender, free and reduced-price lunch status, English learner status, and special education status). To examine the enactment of the mathematical mindset approach, a subset of classroom videos from the camps were collected and analyzed using qualitative methods. Finally, to investigate students' mindsets, interviews with a subset of teachers were conducted and transcripts of these interviews were analyzed.

\section{Student Achievement}

Two data sources were used to examine student achievement: a standardized assessment of conceptual mathematics- MARS tasks-was administered at the start and end of the camps to measure changes in students' mathematical understanding. Participating sites administered four MARS performance tasks at the beginning of camp and on the final day, with the same tasks used for pre and post camp across all grade levels. Each task was scored by an external partner Silicon Valley Mathematics Institute (SVMI) on a point-score analytic rubric for numerical responses and mathematical reasoning. There was a total of 36 possible points across the four tasks. MARS scores were analyzed for all students who met the following criteria: (i) they were in a district that had submitted MARS assessment papers by November 4, 2019; (ii) they had both pre and post camp scores available, and; (iii) they had completed at least two of the four MARS tasks.

To consider change in mathematical understanding, measured through MARS tasks, a composite score was achieved by summing students' scores across the four tasks with the prescore subtracted from the post-score, to give a measure of growth and enable the calculation of main effect sizes, following the same method as the original camp study (Boaler, 2019b). This enabled analysis of gains by district understand the variation of effects, including the relationship between effect size and hours of instruction.

To measure the program's impact on student achievement when students returned to their school classrooms after the conclusion of the summer camps, mathematics grade point average (GPA) were collected for the school year following the mathematics summer camp (2019-2020). A matched comparison analysis (Rosenbaum and Rubin, 1983; Stuart, 2010) was used to analyze the effects of the youcubed camp on students' GPA. The sample included 536 camp participants enrolled in grades 5, 6, and 7 (the camp's focal grades) in 10 districts during the Spring of 2019. This sample included all camp participants for whom baseline GPA, baseline math standardized test score, and the outcome GPA were able to be gathered, making up $64 \%$ of the original sample of camp participants. Students changing school districts was a common reason for missing data.

The analysis was conducted through the creation of a uniform GPA variable across the 10 districts by mapping standards-based grades (which have four levels) onto a standard, 4-point GPA scale (i.e., "advanced" was coded as 4 , "proficient" was coded as 3, "below proficient" was coded as 2 , and "basic" was coded as 1 , equivalent to a D letter grade in the standard GPA scale). Neighbor matching (Abadie et al., 2004) was used to identify comparison students for each camp participant based on proximity in baseline GPA and mathematics standardized test score. The post-youcubed mathematics camp GPA of that comparison student served as the estimate of the grade each camp participant would have received if they had not attended camp. When multiple comparison group students had equally similar baseline grades and scores, this algorithm used the average Fall 2019 GPA of those students as the estimated comparison outcome. To identify the average effect of the youcubed mathematics camp among participants, this approach calculated the difference in average GPA between camp participants and the matched comparison students.

Multiple model specifications were used to assess whether the overall impact estimates were robust. Among models that included the key baseline variables of mathematics GPA and test score, all impact estimates were positive and of a similar magnitude, and the model with the richest set of matching variables (adding race, ethnicity, gender, free and reducedprice lunch (FRPL) status, English language learner (ELL) status, and special education status as matching variables) yielded a very similar impact estimate ( 0.14 GPA points). The chosen model included prior GPA and math score, both to avoid reducing the sample size (thus making the findings as broadly applicable to camp participants as possible) and to prioritize identifying matched comparison students with the most similar prior academic achievement.

\section{Studying the Enactment of the Youcubed Camp Approach}

To capture the teaching that was implemented in the different camps, not only the intended teaching approach, seven classroom videos across four sites were analyzed. All teachers had been asked to record and submit a classroom video of the same task, "Painted Cube" (shown in Figure 2). Across all districts, nine classroom videos were submitted and seven were determined to have strong enough audio and video quality for analysis.

The teaching was analyzed in two different ways. Researchers created content logs (Derry et al., 2010) of approximately 7 hours of video, outlining the events on each video and conducting a time analysis of how many minutes were spent on each segment of the lesson (i.e., task launch, work time, and whole-class 


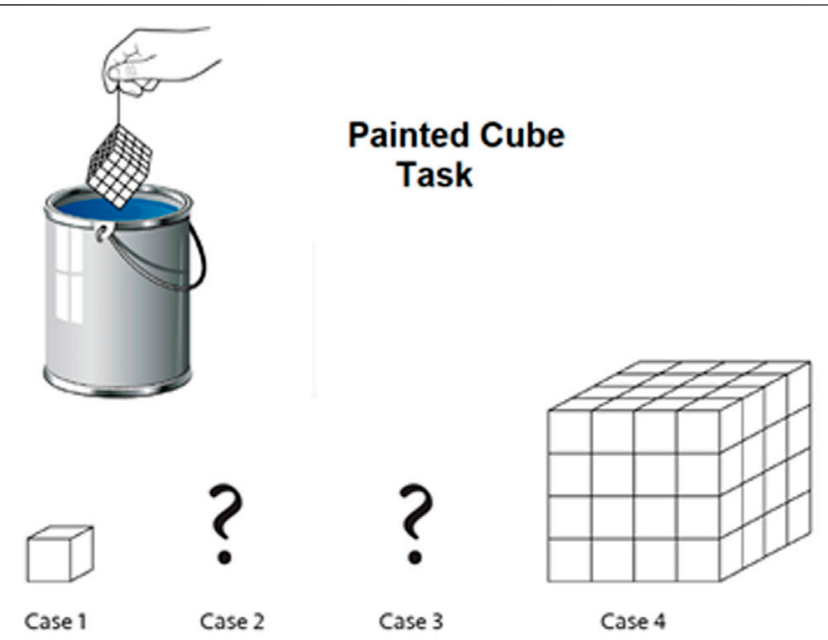

Task Instruction

Imagine that we paint a $4 \times 4 \times 4$ cube blue on every side.

How many of the small cubes have 3 blue faces?

How many have 2 blue faces?

How many have 1 blue face?

How many have not been painted at all?

How many unit cubes have $3,2,1$ or no faces painted in a cube of any size? Think visually!

FIGURE 2 | Painted cube task.

discussion) for each teacher and across the teachers. One of the seven videos was excluded from the time analysis because it only captured one segment of the lesson.

In the second form of analysis, researchers examined the seven videos using the Mathematical Mindset Teaching Guide (https://www.youcubed.org/mathematical-mindset-teachingguide-teaching-video-and-additional-resources/) as a tool for coding classroom practice. An initial video was selected to consider in depth, based on the teacher's implementation of several mathematical mindset teaching practices, which was determined during the content logging process. A team of three researchers then re-watched this video, independently identifying 7-10 "critical moments" in which one of the mathematical mindset teaching practices (Growth Mindset Culture, Nature of Mathematics, Challenge and Struggle, Connections \& Collaboration) was enacted. The fifth practice, assessment, was excluded because it was not feasible to identify the teacher's range of assessment practices in one lesson. After discussing these moments and the extent to which each aligned with the proposed practice, the combined critical moments were developed into a list of indicators for each dimension of each practice. For example, in one critical moment the teacher called on a student to explain their thinking, and when the student asked if they should come up to the board, the teacher said, "whatever you need to do to prove it." This moment was combined with another moment-in which the teacher asked the class questions like "how do you know?"--to create the following indicator for the "Reasoning \&
Multiple Perspectives" dimension of the Nature of Math practice: "students are expected and explicitly invited to bring multiple ideas to the task and justify/reason through their ideas (in writing and/or verbally)." This initial draft was then tested on two contrasting cases from two different sites, for which researchers identified evidence that either validated an indicator or suggested a need to refine an indicator (e.g., rewording, clarifying, adding). These pieces of evidence were discussed until consensus was reached, which led to refinement of the indicators. For example, the previously mentioned indicator was validated by a moment in which a different teacher asked the class for different answers following the sharing of a solution from one student. The revised indicators were then used to code the remainder of the data set for critical moments in which mathematical mindset teaching practices were enacted.

\section{Studying Student Mindsets and Engagement with Mathematics}

To consider changes in students' mindsets and engagement with mathematics, semi-structured interviews (Glesne, 2005) were conducted with teachers during the 2019-2020 school year, following the implementation of the youcubed camp. Teachers were recruited for interviews and the 20 that were interviewed came from six districts, representing both the highest and lowest achieving camps amongst the group based on MARS effect sizes. These interviews lasted approximately $45 \mathrm{~min}$. The interviews 
TABLE 3 | Pre/post design results by district, listed by effect size.

\begin{tabular}{|c|c|c|c|c|c|}
\hline Sample & Obs & Pre-test mean & Post-test mean & $\begin{array}{l}\text { Difference (post } \\
\text { - pre) }\end{array}$ & $\begin{array}{c}\text { MARS effect } \\
\text { size }\end{array}$ \\
\hline All School Sites & 825 & 6.6 & 8.8 & 2.2 & $0.52^{\star \star \star}$ \\
\hline District 8 & 25 & 4.16 & 8.32 & 4.16 & $0.96^{* \star \star}$ \\
\hline District 5 & 45 & 6.09 & 8.91 & 2.82 & $0.65^{\star \star \star}$ \\
\hline District 6 & 34 & 5.09 & 7.76 & 2.68 & $0.62^{* \star}$ \\
\hline District 2 & 234 & 6.71 & 9.32 & 2.62 & $0.61^{\star \star \star}$ \\
\hline District 10 & 20 & 6.25 & 8.7 & 2.45 & $0.57^{\star \star \star \star}$ \\
\hline District 1 & 289 & 7.88 & 9.93 & 2.06 & $0.48^{\star \star \star}$ \\
\hline District 9 & 34 & 3.24 & 4.97 & 1.74 & $0.40^{\star \star \star}$ \\
\hline District 3 & 42 & 6.02 & 7.67 & 1.64 & 0.38 * \\
\hline District 4 & 52 & 5.63 & 6.69 & 1.06 & $0.25^{\star}$ \\
\hline District 7 & 50 & 5.38 & 6.4 & 1.02 & 0.24 \\
\hline
\end{tabular}

Source: MARS scores provided by camps.

Note: Effect sizes are calculated using the same approach adopted in previous research on the youcubed mathematics camp, dividing the difference in raw score by the in-sample standard deviation of the raw pre-test score. ${ }^{* *} \mathrm{p}<0.01,{ }^{* *} \mathrm{p}<0.05,{ }^{*} \mathrm{p}<0.1$.

were conducted and recorded via Zoom, and transcripts of the audio were analyzed. Two members of the research team coded the transcripts to systematically identify instances in which teachers provided detail of students' experiences in the youcubed classrooms. These excerpts were then open coded for emergent themes around students' mindsets and relationships with mathematics, after which analytic memos were written (Emerson et al., 2011) and a codebook was created. Two researchers then re-coded the excerpts using this codebook. Next, a theme analysis was conducted on excerpts from the three most common codes (tasks, student engagement, and student belief). Finally, researchers calculated the presence and co-occurrence of these three codes across the data set to quantify these themes.

\section{RESULTS}

Analyses revealed that students' mathematics achievement both at the conclusion of camp and in the following school year significantly increased, as measured by MARS scores and mathematics GPA. To better understand the mechanism for this change, teachers' enactment of the mathematical mindset teaching practices was analyzed. This analysis of teaching revealed that students were given significant time to grapple with open tasks in summer camp. Additional analyses of teachers' interviews showed that students' experiences with open tasks was a significant factor in students' changed mindset and engagement with mathematics.

\section{MARS Results}

Students who attended the youcubed camps achieved at significantly higher levels at the conclusion of the camps, as evidenced by a significant difference in pre/post MARS assessments. The average gain score for participating students across all sites was 0.52 standard deviation units (SD), equivalent to 1.6 years of growth in math. On average, at baseline, camp participants received 6.6 points out of a total of 36 on the 4 MARS tasks, whereas the mean score after the camp was 8.8 , a gain of 2.2 points that was statistically significant with a 99\% degree of confidence. There was variation across ten districts in the size of gains students demonstrated, with gains ranging from $0.24 \mathrm{SD}$ to $0.96 \mathrm{SD}$ (i.e., 1.02 to 4.16 points, respectively). In nine out of the ten camps, gains were statistically significant with a $90 \%$ of confidence. Table 3 presents the results both in the aggregate and by district. The overall sample result of $0.52 \mathrm{SD}$ is lower than the original youcubed summer camp at Stanford of 0.91 SD.

To consider the impact of the teaching time in different camps, investigation of correlations between the amount of instruction provided by a camp (in days of camp and hours of instruction) and the growth in learning students demonstrated (the effect sizes of the learning gains) were conducted. These showed moderate, positive correlations in the total number of days of camp duration $(r=0.65)$ and total number of hours $(r=0.58)$ each site devoted to the youcubed camp approach. Figure 3 present scatterplots of these relationships. The correlation with total days is statistically significant at the 0.05 level.

The MARS gains showed that camps who offered the mathematical mindset approach for more days and hours, achieved significantly larger gains. There was little evidence of a difference in MARS gains based on recruitment approach (see Table 5).

\section{Post Camp Grades}

When the students returned to their regular mathematics classes in their school district they experienced a variety of forms of instruction. The students who had attended the camps were compared with students in their districts who were at similar levels of achievement but had not attended the camps. This analysis showed that at the end of the first term or semester back at school, the students who attended the youcubed summer camp achieved a significantly higher mathematics GPA $(p<$ $0.01, \mathrm{n}=2,417)$. On average, students who attended camp had a math GPA that was 0.16 points higher than similar nonattendees (i.e., students from the same district and grade and who had a similar baseline math GPA and test score) (Table 4). In addition, compared to control students, camp participants 

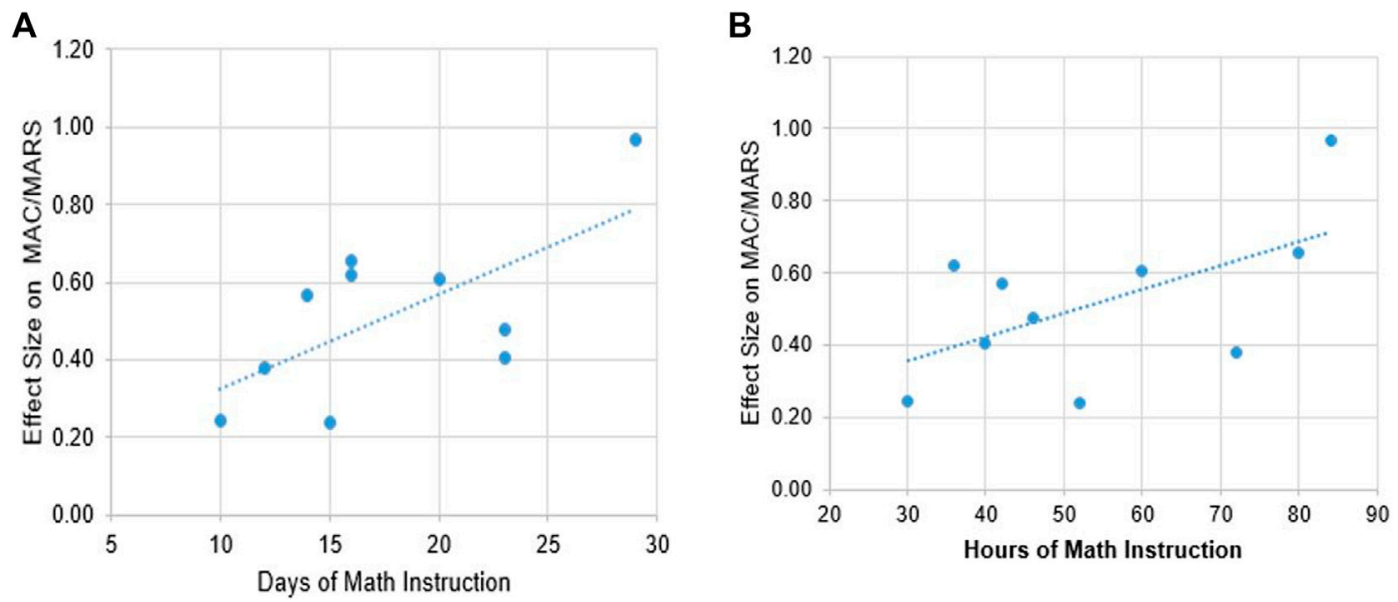

FIGURE 3 | (A) Effect size of MARS by number of days of MMSP instruction. (B) Effect size of MARS by number of hours of MMSP instruction.

TABLE 4 | Estimated effects of the MMSP on student math grades.

Outcome measure

Math GPA (4-point scale)

Percentage with grade of $B$ or better

Percentage with grade of $\mathrm{D}$ or worse
Camp participants

2.62

54.3

15.7
Matched non-participants

2.46

48.5

20.9
Effect

$0.1579^{\star \star \star}$

$5.83^{\star \star *}$

$-5.23^{\star \star \star}$

Notes: These estimates consider fifth, sixth and seventh graders in all school sites. In all estimates, sample size consists of 536 camp participants and 1,881 matched non-participants.

${ }^{* * *} \mathrm{p}<0.01,{ }^{* *} \mathrm{p}<0.05,{ }^{*} \mathrm{p}<0.1$.

TABLE 5 | Estimated impacts on math GPA and gains on MAC/MARS among subgroups of program sites.

\begin{tabular}{lcccc} 
& Math GPA & Sites & MARS Gain & Sites \\
\hline $\begin{array}{l}\text { District Recruitment } \\
\text { Remediating (score below avg.) }\end{array}$ & $0.2058^{\star \star \star}$ & 3 & $0.5239^{\star \star \star}$ & 3 \\
$\quad 0.1045$ & 7 & $0.4965^{\star \star \star}$ & 7 \\
Regular (score at median) & & & & \\
Lamp Dosage & $0.2683^{\star \star \star}$ & 4 & $0.4328^{\star \star \star}$ & 3 \\
Medium (40-60 h) & 0.0934 & 3 & $0.5341^{\star \star \star}$ & 3 \\
High (72-84 h) & 0.0404 & 3 & $0.6302^{\star \star \star}$ & 3
\end{tabular}

Note: Impact on math GPA results come from matched comparison estimates while MARS gain results come from t-tests. The GPA analysis includes one district that did not provide MARS scores, and the MARS analysis similarly includes one district that did not provide GPA records, so the samples are not identical between the two analyses. Districts were classified as "remediating recruitment" if the standardized difference of the average test score between camp and comparison students was below 0.4 standard deviations. Otherwise, they were classified as "regular recruitment." ${ }^{* *} \mathrm{p}<0.01,{ }^{* *} \mathrm{p}<$ $0.05,{ }^{*} p<0.1$.

were 6 percentage points more likely to receive a grade of B or higher, and 5 percentage points less likely to receive a grade of $\mathrm{D}$ or lower (Table 4).

Among the seven sites that shared science GPA data, a matched-comparison analysis indicated that camp participants also had slightly higher science GPAs than similar nonparticipants, but that difference-0.11 GPA points-was not statistically significant at the $5 \%$ level.
Overall, exploratory subgroup analyses suggest that the mathematical mindset intervention had a similar impact for students with different demographic characteristics including students of different racial groups, English Learners, and students who received low or average grades at baseline (Table 5). The only exception to the overall pattern of similar impacts among subgroups was that the large impact on GPA for special education students (0.46 GPA points) was significantly different from the impact for non-special education students ( 0.10 GPA points).

At camps that targeted recruitment to students with substantially lower math test scores than the district average, impacts on math GPA were larger (Table 5). The pattern in GPA impacts from these exploratory analyses suggests that the mathematical mindset approach particularly benefits students with a lower level of baseline math knowledge, even with a modest number of hours of instruction.

\section{Analyses of Teaching}

Video analyses of teaching were conducted to consider the aspects of mathematical mindset teaching practices that brought about these positive gains in mathematics achievement, and that stand in contrast to more typical forms of mathematics teaching ( $\mathrm{Li}$ and Schoenfeld, 2019). The task that was the subject of analysis (see Figure 2, Painted Cube) prompts students to consider the faces of the small $1 \times 1 \times$ one cubes that comprise a $3 \times 3 \times$ three cube--a 


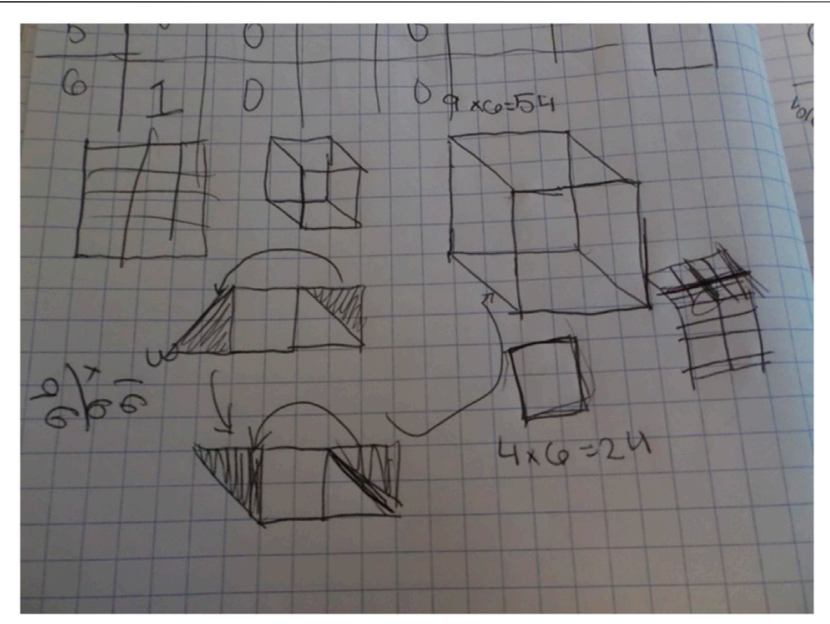

FIGURE 4 | Drawings of cubes from student notebook.

challenging task that gives students opportunities to struggle and gives teachers opportunities to share messages of the value of struggle as well as the value of visual thinking. The task is low floor-all students can build with cubes and think about patterns-and high ceiling, as the upper ends of the task involve forming different expressions, linear, quadratic, and cubic. The different teachers studied all invited students to build different sized cubes using sugar cubes--beginning with a $3 \times 3 \times$ three cube and then extending to a $4 \times 4 \times$ four cube-and to engage in three-dimensional visualization and drawing, which encouraged students to experience math physically, see it visually, and think about generalization. To help them draw different sized cubes, students were provided notebooks with squared paper, as shown in one student's journal in Figure 4. These critical moments in which teachers supported students with the resources and time to deeply explore one problem through multiple approaches served as evidence of their enactment of the mathematical mindset teaching practice of nature of math and the dimensions of "reasoning and multiple perspectives" and "depth over speed".

To support students in finding and extending patterns during their exploration, teachers in six out of seven classrooms created a table on the whiteboard to document the number of cubes within each type of cube that would have each amount of their faces shaded. Of these six classrooms, two teachers constructed partial tables, which documented the number of cubes with each number of faces shaded for solely a $3 \times 3 \times$ three cube or both a $3 \times 3 \times$ three and $4 \times 4 \times$ four cube. The other four teachers constructed tables that extended to $5 \times 5 \times$ five and $\mathrm{n} \times \mathrm{n} \times \mathrm{n}$ cubes. An example of this table, written by a student in their notebook, is shown in Figure 5.

Surprisingly perhaps, teachers rarely shared explicit growth mindset messages during this task, but they frequently supported a growth mindset culture in implicit ways, as evidenced by critical moments in which teachers pushed students to justify their thinking, invited students to come up to the board to share their thinking, gave students time to grapple with the task on their own before intervening, and praised students' thinking and struggle.

Time analysis showed that teachers afforded students ample time to grapple with and persist through the task, supporting the students in encountering challenge and struggle-a key aspect of a mathematical mindset teaching approach. Teachers launched the task for approximately 5 minutes on average and then allowed students to grapple with the task--building cubes, collaborating with peers, and recording in their journals or on chart paper--for an average of $53 \mathrm{~min}$. The open nature of the task meant that even as students figured out one part of the question there were still other areas to explore. After students had sufficient work time and most students had moved beyond the original question to work on the $4 \times 4 \times 4$ cube or generalized even further, the teacher then facilitated a whole class discussion to synthesize the ideas from multiple student groups. This was noted in five of the six videos and lasted approximately 9 minutes on average. Analyses revealed that students were afforded significant time to work on the task in groups and that teachers pushed students to justify their thinking and to connect to each other's ideas in whole-class discussions.

The teaching analyses revealed that teachers offered students multiple opportunities to experience mathematical ideas in multidimensional ways--they saw a 2 -D representation of the cube, built a 3-D model, drew different sized cubes, collected and recorded patterns, organized their thinking, discussed ideas with each other, and considered generalization of different sized cubes. Painted Cube was one of many open tasks in the summer camp curriculum, which afforded students a new mathematical experience, through which they could experience important brain connections, as they saw and experienced mathematics in different ways. An absence of any tests or grading practices during the weeks of the camps was also an important feature designed to avoid the fixed messages associated with such practices (Kraker-Pauw et al., 2017). Teachers chose instead to

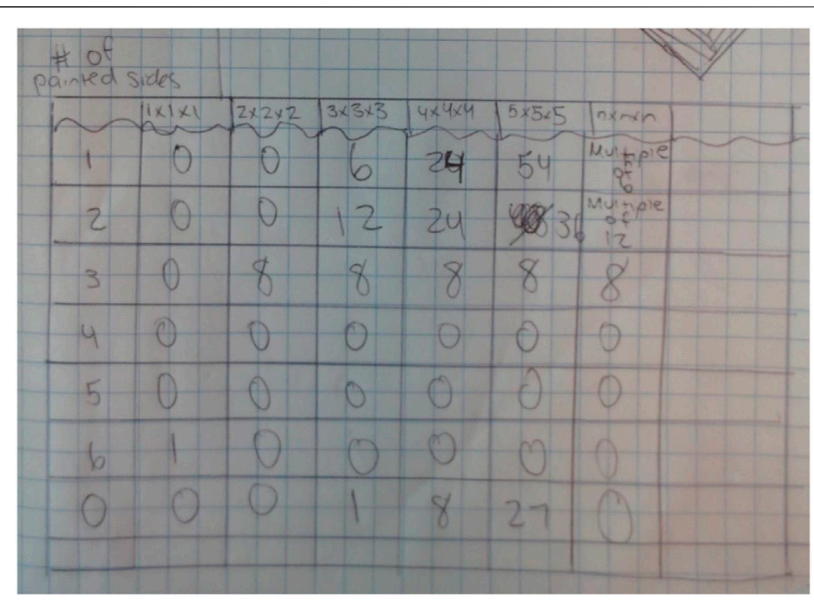

FIGURE 5 | Table of patterns from student's notebook. 
give diagnostic feedback to students as they worked on open tasks (Black and Wiliam, 1998).

\section{Students' Mindsets and Engagement with Mathematics}

The main focus of the study reported in this paper was the relationship between a mathematical mindset teaching approach and student understanding and achievement, but teacher interviews conducted with 20 teachers also enabled consideration of the students' shifts in engagement and mindset, as observed by the teachers. All of the interviews were coded and the three most common codes that emerged, as teachers discussed the students' experiences, were: tasks, student engagement, and student beliefs. Theme analysis across these three codes showed that teachers reported that a significant factor in the students' engagement in the mathematics in camp came from the openness of tasks, which also helped support students' changes in mindsets.

All 20 of the teachers interviewed shared details of how the summer camp curriculum impacted students' engagement and mindsets positively. Sixteen of the teachers $(80 \%)$ reported the importance of the tasks allowing students to develop and share their own thinking and reasoning--rather than share a single method or answer--and the ways this shifted the dynamics of the classroom. The 16 teachers differed in the particular aspect(s) of the tasks they foregrounded in their interviews: $30 \%$ foregrounded the opportunities for multiple approaches to the tasks, $25 \%$ foregrounded the open and explorative nature of the tasks, $25 \%$ foregrounded the focus on students' explaining their thinking, and $20 \%$ foregrounded the opportunities for students to experience mathematical ideas physically. The teachers explained that when their students shared their thinking with one another, they saw that there were multiple ways to think about the same problem, shifting students' ideas about what it means to solve a mathematics problem. The teachers noted the multiple entry points for students to participate and engage in tasks and the multiple ways students could find success. These features of tasks resulted in an overall increase in student excitement and engagement and a decrease in anxiety and fear of making mistakes.

Interview analyses also revealed that the majority of teachers observed shifts in students' engagement throughout the summer camp. Fifteen of the teachers (75\%) commented on two types of shifts in student engagement: shifts at the whole-class level and shifts for particular groups of students or individual students. For both types of shifts in engagement, teachers shared stories of students increasing their participation in groupwork, sharing and showing their thinking more readily, persisting on problems rather than shutting down, and building confidence in thinking mathematically. Eight of the teachers (40\%) shared that their students displayed excitement while doing mathematics tasks (to the point of not wanting to go to recess or lunch).

Additionally, many teachers connected the task not only to increased engagement but to students' changed beliefs about themselves as mathematics learners. Sixteen $(80 \%)$ of the teachers commented on shifts in two types of student beliefs: beliefs about the nature of mathematics and the ways students could engage in the subject $(n=6)$ and beliefs about their ability to be successful $(n=10)$. Teachers shared that students changed their ideas of mathematics as being a closed subject of speed, individual work, and procedures, to regarding mathematics as a subject in which they could engage deeply, visually and collaboratively. Additionally, teachers noted that many students who had had previously negative experiences with math, built confidence in their abilities as "doers of mathematics," became excited about mathematics, and developed positive attitudes towards their mathematics learning.

Many of the teachers shared stories of student transformation, particularly highlighting students who had previously been unsuccessful, shedding negative ideas about the nature of mathematics and their potential, and engaging in new ways. We close this section of the paper with one of the teacher's reflections:

"I had a student who really, really struggled. We had the entrance exam for her in the Youcubed program and she did not do very well at all, I mean very close to zero. What I found was by the end of the summer, she was more confident to answer those questions, she had no fear about this test, she had no remorse about this test, she put answers on paper, she thought about nontraditional ways, she put a lot more time and energy into it and she did exceptional on it regarding her first score. She went from zero to a passing score, which for somebody like that is a really, really important thing, it builds that confidence huge. So I can just. I'll never forget this one student who really had no way to access that information when she came into the camp, but only five weeks later, she could develop that into some really, really solid thinking. And she wasn't necessarily always right, but you could see her thinking progress, and that was a beautiful thing."

\section{DISCUSSION AND CONCLUSION}

The summer camp intervention built upon research from psychology, neuroscience, and mathematics education, in designing new ways for students to experience mathematics (Wittmann, 1995) as an open, visual and creative subject, that we describe as a Mathematical Mindset approach (Boaler, 2016). From psychology, the concept of mindset and the importance of helping students believe that they can learn anything, has become widely known in education among teachers and leaders. In a national survey of teachers in the U.S., $98 \%$ reported that growth mindsets were important for students to have, and $90 \%$ reported that they associated students' mindsets with increased effort and persistence. Strikingly, only $20 \%$ of the same sample believed that they could foster a growth mindset through their teaching, and $85 \%$ said they needed professional development to learn about ways to encourage mindset through teaching (Education Week research center, 2016). The disconnect between teachers' practices and mindset messaging is well known by leaders and becoming established in different research studies. Research that has studied teachers' assessment practices, a key way in which mindset ideas-fixed or growth-are communicated, has found 
that teachers often reveal growth mindset beliefs and ideas but then assess students with closed practices-giving students no opportunity to improve or "grow" their learning and achievement (Kraker-Pauw et al., 2017). Other studies reveal disconnects between mindset messages and the mathematics problems and tasks used in classrooms, with closed and narrow mathematics tasks causing students to believe that students are smart or they are not, and that speed is the most important part of mathematics success (LaMar et al., 2020).

An important feature of a growth mindset approach to learning is a comfort with struggle and the belief that struggle is good for learning. Studies of beginning college students, who were asked to engage in complex tasks, found that students were uncomfortable with struggle and their lack of awareness of the value of struggle caused them to avoid complex tasks (Deslauriers et al., 2019). The need to encourage student comfort with struggle, and student awareness of the value of struggle for brain development (Coyle, 2018) is why messages of struggle are centralized in the mathematical mindset approach. Alongside the messages that teachers were trained to give, the tasks that were part of the youcubed curriculum required high level thinking and gave students multiple opportunities to struggle-in supportive classroom environments. By designing instructional tasks and teaching strategies that were fully aligned with growth mindset, the project moved beyond what has been termed a "false growth mindset" approach - of encouraging messages with no change in teaching (Dweck, 2015; Dweck, 2016; Sun, 2018; Sun, 2019). Students received not only growth mindset messaging, but teaching practices that reflected and reinforced this messaging.

The mathematics tasks, that emerged clearly as pivotal in the students' experiences, from the teacher interviews, and that we have described as low floor and high ceiling, also had another important feature-they were mathematically interesting to students. Other studies have highlighted the value of students working on tasks that are based in realistic contexts, and that give students opportunities to consider and tackle social injustices (Gutstein, 2016). The tasks in the youcubed camps did not do this, instead they centered the idea of mathematics being 'the science of patterns' (Wittmann, 1995; Devlin, 1996) and they invited students to investigate patterns in the borders of squares, in the growth of cubes, in dot cards and number talks, in displays of number visuals, in Pascal's triangle, and in other examples of what some describe as "pure mathematics." In both the original youcubed camp and the camps taught in ten districts, that are the focus of this paper, students were fascinated by these mathematical investigations and deeply engaged in the discovery of patterns, confirming what Devlin has claimed to be a natural human desire-to study and understand patterns (Devlin, 1996). Perhaps surprisingly to some, these pattern based tasks, taught students school mathematics-including the mathematics of number sense, geometry, and algebra. They also contributed to the pursuit of equitable outcomes, helping students who had previously under achieved, see a future for themselves in mathematics, and other STEM subjects.

This study had several limitations and some unanswered questions. Missing data, due to student turnover and the difficulties of following students who changed districts, was one challenge. One unanswered question is why some camps raised students' achievement significantly more than others, a question that could be investigated in a further study.

Despite these limitations and unanswered questions, the data reported shows that a mathematics approach that is based on mindset and neuroscience, that enables students to embrace struggle and to encounter mathematics in multiple ways, can have a transformative impact on students. This approach is not one that is typically used in schools, partly because of the pressure teachers feel to "cover" the curriculum, and to prepare students for narrow tests, as well as the textbooks on offer to teachers, usually filled with narrow questions. For these reasons the teachers who took part in the study believed that a summer camp is needed, free from these constraints, to unlock students' potential (Boaler, 2019a), and to help them approach school mathematics differently. Some teachers have learned about the mathematical mindset approach and have infused it into their regular classroom teaching, with resulting achievement gains for students (Anderson et al., 2018).

The study reported in this paper adds to this important evidence-showing that a two-to-four-week summer camp sharing a mathematical mindset approach can have a transformative impact on student mathematics achievement. We hope that these different forms of evidence, from summer camp and from school teaching, will prompt policy makers to reconsider the mathematics approaches they encourage in schools-that contravene mindset messages and have resulted in widespread under achievement across the US. When students are released from negative ideas about mathematics and themselves, they learn and approach mathematics differently, and begin a changed, mindset infused, pathway.

\section{DATA AVAILABILITY STATEMENT}

The original contributions presented in the study are included in the article/Supplementary Material, further inquiries can be directed to the corresponding author.

\section{ETHICS STATEMENT}

The studies involving human participants were reviewed and approved by Institutional Review Board, GSE, Stanford University. Written informed consent to participate in this study was provided by the participants' legal guardian/next of kin. Written informed consent was obtained from the individual(s), and minor(s)' legal guardian/next of kin, for the publication of any potentially identifiable images or data included in this article.

\section{AUTHOR CONTRIBUTIONS}

JB designed and directed the study, GP-N, JD, and MS-A ran statistical analyses, TL and ML led the analysis of teaching. The full team interpreted results and contributed the writing and revising process. 


\section{FUNDING}

This report is based on research funded in part by the Bill and Melinda Gates Foundation. The findings and conclusions contained within are those of the authors and do not necessarily reflect positions or policies of the Bill and Melinda Gates Foundation.

\section{REFERENCES}

Abadie, A., Drukker, D., Herr, J. L., and Imbens, G. W. (2004). Implementing Matching Estimators for Average Treatment Effects in Stata. Stata J. 4 (3), 290-311. doi:10.1177/1536867x0400400307

Anderson, R., Boaler, J., and Dieckmann, J. (2018). Achieving Elusive Teacher Change through Challenging Myths about Learning: A Blended Approach. Educ. Sci. 8 (3), 98. doi:10.3390/educsci8030098

Aronson, J., Fried, C. B., and Good, C. (2002). Reducing the Effects of Stereotype Threat on African American College Students by Shaping Theories of Intelligence. J. Exp. Soc. Psychol. 38 (2), 113-125. doi:10.1006/jesp.2001.1491

Black, P., and Wiliam, D. (1998). Assessment and Classroom Learning. Assess. Educ. Principles, Pol. Pract. 5 (1), 7-74. doi:10.1080/0969595980050102

Blackwell, L. S., Trzesniewski, K. H., and Dweck, C. S. (2007). Implicit Theories of Intelligence Predict Achievement across an Adolescent Transition: A Longitudinal Study and an Intervention. Child. Dev. 78 (1), 246-263. doi:10.1111/j.1467-8624.2007.00995.x

Boaler, J., Dieckmann, J. A., Pérez-Núñez, G., Sun, K. L., and Williams, C. (2018). Changing Students Minds and Achievement in Mathematics: The Impact of a Free Online Student Course. Front. Educ. 3, 26. doi:10.3389/feduc.2018.00026

Boaler, J. (2019a). Limitless Mind: Learn, lead, and Live without Barriers. New York, NY: HarperCollins.

Boaler, J. (2016). Mathematical Mindsets: Unleashing Students' Potential through Creative Math, Inspiring Messages and Innovative Teaching. San Francisco, CA: John Wiley \& Sons.

Boaler, J. (2022). Mathematical Mindsets: Unleashing Students' Potential through Creative Math, Inspiring Messages and Innovative Teaching. 2nd Edition. San Francisco, CA: John Wiley \& Sons.

Boaler, J. (1998). Open and Closed Mathematics: Student Experiences and Understandings. J. Res. Math. Educ. 29 (1), 41-62. doi:10.5951/ jresematheduc.29.1.0041

Boaler, J. (2019b). Prove it to Me!. Maths. Teach. Middle Sch. 24 (7), 422-428. doi:10.5951/mathteacmiddscho.24.7.0422

Boaler, J. (2002). The Development of Disciplinary Relationships: Knowledge, Practice and Identity in Mathematics Classrooms. Learning Mathematics 22 (1), 42-47. Available at: https://www.jstor.org/stable/40248383 (Accessed July 01, 2021)

Bransford, J. D., Brown, A. L., and Cocking, R. R. (2000). How People Learn, 11. Washington, DC: National academy press.

Cabana, C., Shreve, B., Woodbury, E., and Louie, N. (2014). Mathematics for Equity: A Framework for Successful Practice. New York, NY: Teachers College Press.

California Department of Education (CD) (2021). California Digital Learning and Standards Guidance. CDE, May 2021. Available at: https://www.cde.ca.gov/ci/ $\mathrm{cr} / \mathrm{dl} /$ dlintergstdsguidance.asp (Accessed July 01, 2021).

Coyle, D. (2018). The Culture Code: The Secrets of Highly Successful Groups. New York, NY: Bantam.

Derry, S. J., Pea, R. D., Barron, B., Engle, R. A., Erickson, F., Goldman, R., et al. (2010). Conducting Video Research in the Learning Sciences: Guidance on Selection, Analysis, Technology, and Ethics. J. Learn. Sci. 19 (1), 3-53. doi:10.1080/10508400903452884

Deslauriers, L., McCarty, L. S., Miller, K., Callaghan, K., and Kestin, G. (2019). Measuring Actual Learning versus Feeling of Learning in Response to Being Actively Engaged in the Classroom. Proc. Natl. Acad. Sci. U S A. 116 (39), 19251-19257. doi:10.1073/pnas.1821936116

Devlin, K. (1996). Mathematics: The Science of Patterns: The Search for Order in Life, Mind and the Universe. New York, NY: Macmillan.

\section{ACKNOWLEDGMENTS}

The authors wish to recognize Cathy Williams, Executive Director of youcubed at Stanford as a co-designer of the summer camp curriculum and member of the research team. The team also would like to acknowledge Gregory Chojnacki, senior researcher at Mathematica, for his invaluable assistance with this research.

Dweck, C. (2015). Carol Dweck Revisits the Growth Mindset. Education Week 35 (5), 20-24. Available at: https://www-edweek-org.stanford.idm.oclc.org/ leadership/opinion-carol-dweck-revisits-the-growth-mindset/2015/09 (Accessed July 01, 2021)

Dweck, C. (2007). Mindset: The New Psychology of Success. New York: Ballantine Books.

Dweck, C. (2016). What Having a "Growth Mindset" Actually Means. Harv. Business Rev. 13, 213-226. Available at: https://hbr.org/2016/01/what-havinga-growth-mindset-actually-means (Accessed July 01, 2021)

Emerson, R. M., Fretz, R. I., and Shaw, L. L. (2011). Writing Ethnographic Fieldnotes. 2nd Edition. Chicago, IL: University of Chicago Press.

Glesne, C. (2005). "Making Words Fly: Developing Understanding through Interviewing," in Becoming Qualitative Researchers: An Introduction (Boston, MA: Pearson Publishing).

Good, C., Aronson, J., and Inzlicht, M. (2003). Improving Adolescents' Standardized Test Performance: An Intervention to Reduce the Effects of Stereotype Threat. J. Appl. Develop. Psychol. 24 (6), 645-662. doi:10.1016/j.appdev.2003.09.002

Gresalfi, M. S., and Cobb, P. (2006). Cultivating Students' Discipline-specific Dispositions as a Critical Goal for Pedagogy and Equity. Pedagogies: Int. J. 1 (1), 49-57. doi:10.1207/s15544818ped0101_8

Gutstein, E. R. (2016). "Our Issues, Our People-Math as Our Weapon": Critical Mathematics in a Chicago Neighborhood High School. J. Res. Maths. Educ. 47 (5), 454-504. doi:10.5951/jresematheduc.47.5.0454

Hubbard, E. M., Piazza, M., Pinel, P., and Dehaene, S. (2005). Interactions between Number and Space in Parietal Cortex. Nat. Rev. Neurosci. 6 (6), 435-448. doi:10.1038/nrn1684

Iuculano, T., Rosenberg-Lee, M., Richardson, J., Tenison, C., Fuchs, L., Supekar, K., et al. (2015). Cognitive Tutoring Induces Widespread Neuroplasticity and Remediates Brain Function in Children with Mathematical Learning Disabilities. Nat. Commun. 6 (8453), 1-10. doi:10.1038/ncomms9453

Kohn, A. (2015). The Perils of "Growth Mindset" Education. Why We're Trying to Fix Our Kids when We Should Be Fixing the System. Salon. Aug 16th. Available at: https://www.salon.com/2015/08/16/the_education_ fad thats hurting our_kids what_you need to know about growth mindset_theory_and_the_harmful_lessons_it_imparts/ (Accessed July 01, 2021).

Kraker-Pauw, D., Van Wesel, F., Krabbendam, L., and Van Atteveldt, N. (2017). Teacher Mindsets Concerning the Malleability of Intelligence and the Appraisal of Achievement in the Context of Feedback. Front. Psychol. 8, 1594 doi:10.3389/fpsyg.2017.01594

Kucian, K., Grond, U., Rotzer, S., Henzi, B., Schönmann, C., Plangger, F., et al. (2011). Mental Number Line Training in Children with Developmental Dyscalculia. NeuroImage 57 (3), 782-795. doi:10.1016/..neuroimage.2011.01.070

LaMar, T., Leshin, M., and Boaler, J. (2020). The Derailing Impact of Content standards-an Equity Focused District Held Back by Narrow Mathematics. Int J. Educ. Res. 1, 100015. doi:10.1016/j.ijedro.2020.100015

Li, Y., and Schoenfeld, A. H. (2019). Problematizing Teaching and Learning Mathematics as "Given" in STEM Education. Int. J. STEM Educ. 6, 44 doi:10.1186/s40594-019-0197-9

Maguire, E. A., Woollett, K., and Spiers, H. J. (2006). London Taxi Drivers and Bus Drivers: A Structural MRI and Neuropsychological Analysis. Hippocampus 16 (12), 1091-1101. doi:10.1002/hipo.20233

Menon, V. (2015). "Salience Network," in Brain Mapping: An Encyclopedic Reference. Editor A W. Toga (London: Academic), 2, 597-611. doi:10.1016/ b978-0-12-397025-1.00052-x

Rosenbaum, P. R., and Rubin, D. B. (1983). The central Role of the Propensity Score in Observational Studies for Causal Effects. Biometrika 70 (1), 41-55. doi:10.1093/biomet/70.1.41 
Schneider, M., Grabner, R. H., and Paetsch, J. (2009). Mental Number Line, Number Line Estimation, and Mathematical Achievement: Their Interrelations in Grades 5 and 6. J. Educ. Psychol. 101 (2), 359-372. doi: $10.1037 / \mathrm{a} 0013840$

Schoenfeld, A. H. (2016). Learning to Think Mathematically: Problem Solving, Metacognition, and Sense Making in Mathematics (Reprint). J. Educ. 196 (2), 1-38. doi:10.1177/002205741619600202

Sengupta-Irving, T. (2016). Doing Things: Organizing for agency in Mathematical Learning. J. Math. Behav. 41, 210-218. doi:10.1016/j.jmathb.2015.10.001

Siegler, R. S., and Booth, J. L. (2004). Development of Numerical Estimation in Young Children. Child. Dev. 75 (2), 428-444. doi:10.1111/j.14678624.2004.00684.x

Silver, E. A. (1997). Fostering Creativity through Instruction Rich in Mathematical Problem Solving and Problem Posing. Zentralblatt für Didaktik der Mathematik 29 (3), 75-80. doi:10.1007/s11858-997-0003-x

Silver, E. A., and Stein, M. K. (1996). The Quasar Project. Urban Educ. 30 (4), 476-521. doi:10.1177/0042085996030004006

Stein, M. K., Grover, B. W., and Henningsen, M. (1996). Building Student Capacity for Mathematical Thinking and Reasoning: An Analysis of Mathematical Tasks Used in Reform Classrooms. Am. Educ. Res. J. 33 (2), 455-488. doi:10.3102/ 00028312033002455

Stohlmann, M., Huang, X., and DeVaul, L. (2018). Middle School Students' Mindsets before and after Open-Ended Problems. J. Maths. Educ. Teach. Coll. 9 (2), 587. doi:10.7916/jmetc.v9i2.587

Stuart, E. A. (2010). Matching Methods for Causal Inference: A Review and a Look Forward. Stat. Sci. 25 (1), 1-21. doi:10.1214/09-STS313
Sun, K. L. (2018). Brief Report: The Role of Mathematics Teaching in Fostering Student Growth Mindset. J. Res. Maths. Educ. 49 (3), 330-335. doi:10.5951/ jresematheduc.49.3.0330

Sun, K. L. (2019). The Mindset Disconnect in Mathematics Teaching: A Qualitative Analysis of Classroom Instruction. J. Math. Behav. 56, 100706. doi:10.1016/ j.jmathb.2019.04.005

Wittmann, E. C. (1995). Mathematics Education as a ?design Science? Educ. Stud. Math. 29 (4), 355-374. doi:10.1007/bf01273911

Conflict of Interest: The authors declare that the research was conducted in the absence of any commercial or financial relationships that could be construed as a potential conflict of interest.

Publisher's Note: All claims expressed in this article are solely those of the authors and do not necessarily represent those of their affiliated organizations, or those of the publisher, the editors and the reviewers. Any product that may be evaluated in this article, or claim that may be made by its manufacturer, is not guaranteed or endorsed by the publisher.

Copyright (C) 2021 Boaler, Dieckmann, LaMar, Leshin, Selbach-Allen and PérezNúñez. This is an open-access article distributed under the terms of the Creative Commons Attribution License (CC BY). The use, distribution or reproduction in other forums is permitted, provided the original author(s) and the copyright owner(s) are credited and that the original publication in this journal is cited, in accordance with accepted academic practice. No use, distribution or reproduction is permitted which does not comply with these terms. 